Within each morphological type, the mass of LD muscle supported by each of the thoracic or lumbar vertebrae was highly variable along the backbone. When the number of vertebrae increased the distribution of its mass changed by a dilution phenomenon resulting from an increase in the length of the bone support of LD muscle.

When expressed in percentage of the total mass supported by each of the thoracic and lumbar vertebrae, the distribution of $L D$ muscle seemed to be the same in normal and in hypertrophied animals, in spite of the large reduction of backbone length in the latter.

\title{
Rearing houses for early weaned piglets: e ffect of climatic conditions and inside housing design on performances
}

\author{
J. LE DIVIDICH \\ Station de Recherches sur l'Élevage des Porcs, \\ Centre national de Recherches zootechniques, I.N.R.A., \\ 78350 Jouy-en-Josas (France)
}

This paper reports the most recent works about the housing of early weaned piglets (between 3 and 4 weeks of age) reared in groups on slatted floor. The effects of the bioclimatic environment parameters of the weaning house (temperature, relative humidity, velocity of the air) on the growth performance and the energy and nitrogen metabolism of piglets are analysed in the first part of the report. The effect of the weaning pen design (nature of the floor, surface per animal, number of piglets per pen) on growth and health are discussed in the second part.

The following main conclusions can be drawn from the results:

- The optimum temperature (dry bulb) for growth is high $\left(26\right.$ to $28^{\circ} \mathrm{C}$ ) during the first week after weaning corresponding to a period of low feed consumption in the piglet; it decreases, parallel to the temperature of thermal comfort, to $20^{\circ} \mathrm{C}$ at $8-9$ weeks of age. A bad regulation of the air temperature (variations of \pm 3 to $4^{\circ} \mathrm{C}$ around the average), especially during the first week after weaning, has a bad effect on the subsequent growth of the piglets and favours the appearance of diarrhoea, their frequency and persistence.

- The velocity of the air must be slow in the period of heating $\leqslant 10 \mathrm{~cm} \mathrm{~s}^{-1}$, corresponding to an hourly retiewal rate of 0.2 to $0.3 \mathrm{~m}^{3}$ per $\mathrm{kg}$ live weight. When, in the absence of heating, the temperature of the house is above the optimum for the piglet, an increase in the velocity of the air until $50-60 \mathrm{~cm} \mathrm{~s}^{-1}$ produces only a significant improvement of the piglet growth if the outside temperature is lower than the optimum temperature for the piglet.

- A relative humidity rate of $5^{\circ}$ to $7^{\circ} \mathrm{p}$. Ioo seems to be optimum.

-When the conditions of the thermal environment are met, the nature of the floor (concrete with straw, slatted floor or concrete) has little influence on the animals'growth.

However, the slatted floor improves the labor productivity and leads to a better utilization of the surface.

- The optimum surface per piglet between 5 and $25-30 \mathrm{~kg}$ live weight is $0.25 \mathrm{~m}^{2}$ according to the hypothesis of a discontinuous batch management of the herd (all-in all-out system). The number of piglets corresponding to an optimum utilization of the surface is 8-Io per pen. 
- The digestive disorders (diarrhoea) following weaning can be largely limited through the control of the climatic conditions, the utilization of slatted floor and especially a discontinuous batch management allowing the cleaning, disinfection and non-utilization of the rooms between each passage of animals.

\title{
Influence of the variations in the main micro-climatic factors of the fattening pig house
}

\author{
C. TEXIER, B. DE LA FARGE, R. GRANIER \\ I.T.P., Service Bâtiment Environnement, \\ I49, whe de Bercy, 75595 Paris Cedex I2 \\ I.T.P., Service Bâtiment et Environnement, \\ 34, bd de la Gare, 31079 Toulouse Cedex \\ I.T.P., Station Expérimentale, Les Cabrièves, \\ I2200 Villefranche-de-Rouergue (France)
}

The experimental building used was a fattening pig house of the Danish type divided into 4 identical rooms with a capacity of 32-40 pigs each. Every room was fitted with a dynamic ventilation system (pressure above atmospheric) with rates ranging between 50 and $740 \mathrm{~m}^{3} / \mathrm{h} /$ pig and a heating system by radiation whose capacity ranged from roo to 260 millithermies /hour/ pig.

By means of an automatic regulator (I.T.P.(*) patent) it was possible at any moment to obtain different ambient conditions from one room to another. animals.

The climatic data were recorded continuously until the slaughtering of the first group of

Six trials were made from 1976 to 1978 from which the following conclusions can be drawn:

- optimum ambient conditions are obtained at high temperatures (at least 20 p. Ioo at the resultant dry temperature),

- association of a low ventilation rate (30 $\mathrm{m}^{3} /$ hour $/ \mathrm{pig}$ ) and a high air velocity $(2.5 \mathrm{~m} / \mathrm{s}$ ) leads to the best growth performance,

- the feeding level should be taken into account when choosing the ambient conditions as ad libitum fed pigs are less susceptible to climatic variations than restricted animals.

\section{Deodorization of pig manure in the piggery}

\author{
B. LEFÈ ÉE, Michèle HEDUIT \\ C.T.G.R.E.F., Division Qualité des Eaux, Pêche et Pisciculture, \\ I4, avenue de St-Mandé, 750I2 Pavis \\ G.I.D.A.|I.T.P., I 49, rue de Bercy, 75595 Paris Cedex I2
}

The aim of this study was to test the efficiency of a treatment of manure deodorization by two air-injectors blowing directly in the dunging gutter of the piggery.

Two fattening periods were observed. In the first one the ventilation times varied from I 2.5 p. IOO $\left(5.2 \mathrm{~kg}\right.$. $\mathrm{O}_{2} /$ day $)$ to 50 p. 100 working $(20.9 \mathrm{~kg} \mathrm{O} /$ day). In the second batch, from 50 p. 100 to $100 \mathrm{p}$. I00.

(*) I.T.P. : Institut Technique du Porc. 